\title{
Vertical Gradient Temperature Difference of the Main Arch with Single Pipe Section in Tibet Based on Statistical Analysis
}

\author{
Tuo Shi $\mathbb{i},{ }^{1}$ Nianchun Deng $\mathbb{D}^{1,2,3}$ Zheng Chen, ${ }^{1,2,3}$ and Haoxu Li $\mathbb{D}^{1}$ \\ ${ }^{1}$ College of Civil Engineering and Architecture, Guangxi University, Nanning 530004, China \\ ${ }^{2}$ Guangxi Special Geological Highway Safety Engineering Technology Research Center, Guangxi University, \\ Nanning 530004, China \\ ${ }^{3}$ Guangxi Long-Span Arch Bridges Engineering Technology Center, Guangxi University, Nanning 530004, China \\ Correspondence should be addressed to Nianchun Deng; dengnch@gxu.edu.cn
}

Received 23 May 2020; Revised 24 July 2020; Accepted 6 August 2020; Published 22 September 2020

Academic Editor: Dora Foti

Copyright (c) 2020 Tuo Shi et al. This is an open access article distributed under the Creative Commons Attribution License, which permits unrestricted use, distribution, and reproduction in any medium, provided the original work is properly cited.

\begin{abstract}
A $75 \mathrm{~m}$ long experimental arch with a $1.6 \mathrm{~m}$ diameter was constructed in Tibet for a one-year test to determine the most unfavourable vertical temperature difference for a single pipe in the main arch of a concrete-filled steel tube arch bridge. Actual temperature observation data were used to analyse the vertical temperature difference in the single circular pipe arch rib using statistical methods. The standard value for the vertical temperature difference in the single pipe under a return period of 50 years was calculated. The results showed that the influence range of the vertical gradient temperature was $25 \mathrm{~cm}$. The vertical temperature difference followed a lognormal distribution, and the standard values of the positive temperature difference at the upper and lower ends of the single pipe were 16 and $10^{\circ} \mathrm{C}$, respectively; the standard values of the negative temperature difference at the upper and lower ends of the single pipe were both $-8^{\circ} \mathrm{C}$ under a return period of 50 years. These results are considerably different from the values specified in the current Chinese code. These could serve as references for calculations involving arch bridges in Tibet with single circular pipes in the main arches.
\end{abstract}

\section{Introduction}

Advancements in the construction technology of concretefilled steel tube (CFST) arch bridges support their economic advantages over a certain period [1-3]. Owing to these economic advantages, there is a demand for building a CFST arch bridge on the Sichuan-Tibet line. The temperature distribution in the bridge shows a typical periodic time history and uneven spatial characteristics affected by the structural form, climate, geographical environment, and other factors; further, there are obvious differences between bridge types and regions [4]. Owing to the lack of long-term observations and the complete use of historical meteorological data, further research on the representative values of the CFST temperature and correlation analysis with meteorological parameters needs to be conducted [5].

The bridge temperature problem has been studied extensively and results are reported. Some scholars have studied the gradient temperature difference in steel box girders. Wang et al. $[6,7]$ relied on the health monitoring systems of several cable-stayed bridges to statistically analyse the temperature difference in flat steel box girders; they obtained the probability densities and standard values of the horizontal and longitudinal temperature differences in the box girder. Wang et al. [8] studied a curved steel box girder bridge in Hangzhou, obtained the nonlinear temperature field under sunshine, and analysed the overturning stability of the bridge.

Some experts have studied the gradient temperature difference in concrete box girders. Leanne et al. [9] calculated the gradient temperature difference in typical concrete box girders and upper structures of a composite steel bridge using a heat flow analysis method based on the meteorological data of two cities in the United States. The values were $10^{\circ} \mathrm{C}$ higher than those specified in the United States codes. Zhou et al. [10] studied the temperature 
distribution of the Humber bridge in England by employing numerical simulations and field measurements. Their results indicated that the transverse temperature difference in the streamlined beam indeed changed; further, they analysed the factors influencing the temperature difference. Lei et al. [11] analysed the transverse and vertical temperature differences of the curved concrete beam bridge with a single-column pier. Their results showed that the displacement and stress caused by the transverse and vertical temperature differences were comparable, and the two temperature difference effects need to be considered simultaneously in the calculations. Liu et al. [12] performed tests and finite element analysis on a concrete beam bridge in a severely cold area; the temperature difference of the bridge in the severely cold area was considerably different from that specified in the Chinese code, which could cause a large tensile stress. Lin et al. [13] estimated the effective temperature of side-byside box girder bridges in different regions and found that it was considerably different from that in the Chinese code. Based on the long-term monitoring data of concrete beam bridges, Li et al. [14] found that the highest temperature estimate provided in the Canadian code was reasonable, and the lowest temperature and temperature difference estimates were relatively small. Song et al. [15] studied the influence of the gradient temperature difference during the construction of beam bridges; the temperature distribution law was obtained by combining the test and numerical simulation results. Further, the deflection caused by the gradient temperature difference needs to be considered in cantilever construction. Rodriguez et al. [16] conducted a long-term observation test on a box girder bridge in the United States; they obtained the highest and lowest average temperatures and positive and negative temperature gradients and then compared them with those specified in the United States codes. They found that the temperature difference at the bottom of the box girder was three times higher than that specified in the United States code.

Most of the above-mentioned studies focused on the vertical and horizontal temperature differences in box girders, and there is no systematic study on the gradient temperature difference in the main arch rib of a CFST arch bridge. Further, most research methods employed the extreme temperature differences obtained experimentally or through simulations and compared them with the corresponding specifications, and only some of them employed probability-statistical methods. Therefore, this study aimed to determine the temperature gradient in a single circular pipe of a CFST arch bridge on the Tibet Plateau in China. Long-term temperature observation tests using a large test arch will be performed; based on the large volumes of test data, we expect that probability-statistical analysis methods would help obtain the temperature difference estimates that satisfy the probability-statistical theory. This is the first study of its kind to study the temperature gradient in a CFST arch bridge with a single circular pipe main arch in a plateau area using probability-statistical methods. The findings of this study can serve as references for determining the temperature difference values of CFST arch bridges in Tibet, China.

\section{Materials and Methods}

A large experimental arch was built in the Shannan area of Tibet. The axial shape of the test arch was similar to the flat setting of the arch crown in the real bridge. The test arch was $75 \mathrm{~m}$ long and $11.25 \mathrm{~m}$ high; the diameter of the steel pipe was $1.6 \mathrm{~m}$, and the wall thickness was $20 \mathrm{~mm}$. The material used for the steel tube was Q235, and the concrete design grade was C60. The concrete mix proportions are listed in Table 1. The specific dimensions of the test arch are shown in Figure 1. Temperature sensors were arranged in section A-A, the arrangements of the measuring points are shown in Figure 2, and a photograph of the test arch is shown in Figure 3.

A thermistor-type thermometer was used, and it was bound with a cross-fixed high-strength insulated steel wire rope. A wireless acquisition system was selected for automatic data acquisition at intervals of $10 \mathrm{~min}$. Concrete was poured into the test arch in June 2018. The test period was from June 2018 to June 2019. The temperature sensor and acquisition instrument are shown in Figure 4. The RT-2 temperature sensors and Sbt-CDM1 automatic acquisition instrument were procured from Jiangsu Subote Co., Ltd. The sensors have a length of $60 \mathrm{~mm}$ and diameter of $8 \mathrm{~mm}$, capable of measuring temperatures from -50 to $150^{\circ} \mathrm{C}$ with an accuracy of $0.1^{\circ} \mathrm{C}$. The sensors were connected with the acquisition instrument. The acquisition instrument has 16 channels. During the experiment, it transmitted the temperature data to the network through wireless signals. The test data were recorded online.

\section{Results and Analysis}

Owing to the influence of sunshine, the temperature field in the main arch section of the CFST arch bridge presents a nonlinear temperature distribution. When the main arch is exposed to sunlight, the temperature at the edge of the main arch section is high and that at the centre is low. Therefore, a temperature gradient occurs in the main arch section.

The vertical temperature gradient curve for a single pipe main arch specified in Chinese code [17] for the design of highway CFST arch bridges is shown in Figure 5; the temperature values are summarised in Table 2. $T_{1}$ represents the temperature difference value at the upper part of the single pipe, and $T_{2}$ represents the temperature difference value at the lower part of the single pipe. Further, $d$ represents the influence range of the gradient temperature difference.

\subsection{Influence Range of Gradient Temperature Difference d.} A previous study [18] reported that the influence range of the gradient temperature difference in a single pipe was $25 \mathrm{~cm}$ $(d=25 \mathrm{~cm})$. To verify its accuracy, theoretical calculations and statistical analyses of the experimental data were carried out.

We have the following assumptions for theoretical calculations: (1) The diameter of the CFST is infinite. (2) The ambient temperature changes as $T=A \sin ((2 \pi / P) \tau)$, where 
TABLE 1: Mix proportions of test concrete $\left(\mathrm{kg} / \mathrm{m}^{3}\right)$.

\begin{tabular}{lc}
\hline Materials & Dosage \\
\hline Cement & 400 \\
Water & 157 \\
Fly ash & 45 \\
Expansion agent & 50 \\
Mineral powder & 25 \\
Silica powder & 10 \\
Sand & 711 \\
Stone & 1052 \\
Water reducer & 10.60 \\
\hline
\end{tabular}

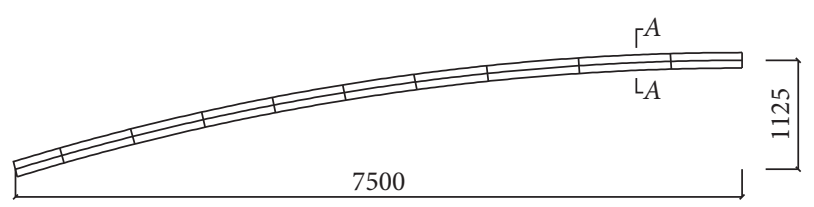

Figure 1: Dimensions of test $\operatorname{arch}(\mathrm{mm})$.

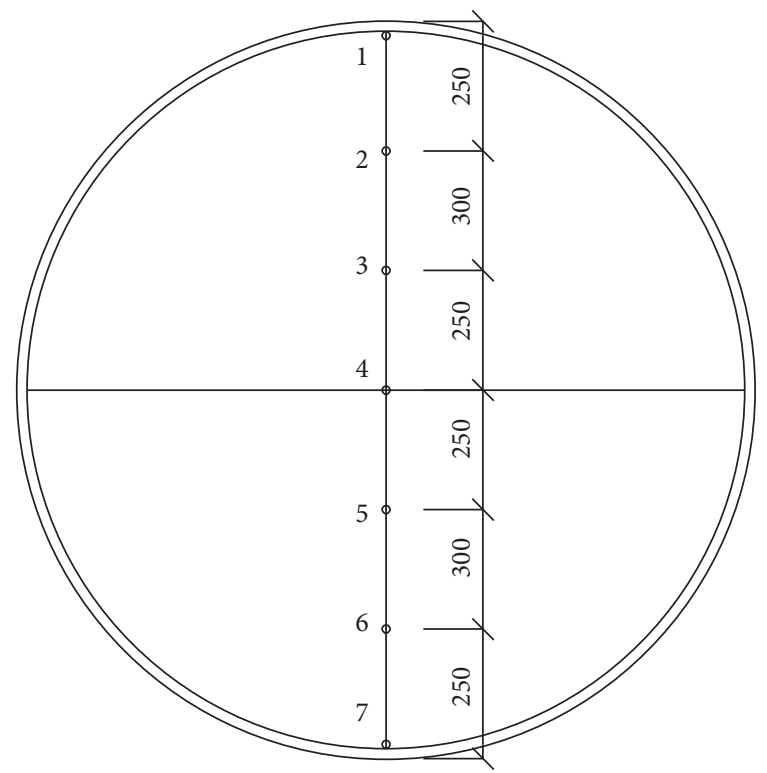

Figure 2: Layout of measuring points in section A-A (mm).

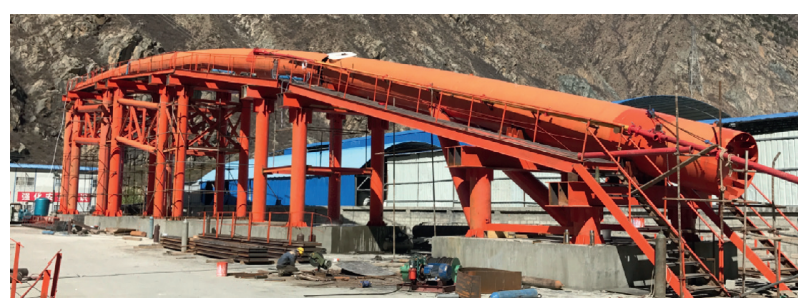

FIGURE 3: Actual photograph of test arch.

$P$ is the variation period of the ambient temperature; and $A$ is the variation amplitude of the ambient temperature. (3) Based on assumption (1), the steel pipe was ignored and concrete was considered to have direct contact with the environment.
To determine the internal temperature of concrete with depth $x$, the following heat conduction equation was used:

$$
\left(\frac{\partial T}{\partial \tau}\right)=a \frac{\partial^{2} T}{\partial x^{2}} .
$$

The boundary conditions are as follows:

$$
\begin{gathered}
\text { When } x=0, \quad-\lambda \frac{\partial T}{\partial x}=\beta\left(T-A \sin \frac{2 \pi \tau}{P}\right), \\
\text { When } x=\infty, \quad T=0 .
\end{gathered}
$$

Without considering the effect of the initial temperature, the solutions satisfying the above conditions are as follows:

$$
\begin{aligned}
& T=A_{0} e^{-x \sqrt{\pi / a P}} \sin \left[\frac{2 \pi \tau}{P}-\left(x \sqrt{\frac{\pi}{a P}}+M\right)\right], \\
& A_{0}=A\left(1+\frac{2 \lambda}{\beta} \sqrt{\frac{\pi}{a P}}+\frac{2 \pi \lambda^{2}}{a P \beta^{2}}\right)^{-0.5}, \\
& M=\tan ^{-1}\left(\frac{1}{1+\sqrt{a P / \pi} \beta / \lambda}\right),
\end{aligned}
$$

where $A$ is the ambient temperature variation amplitude; $A_{0}$ is the concrete surface temperature variation amplitude; $P$ is the ambient temperature variation period; $M$ is the phase difference of the concrete surface temperature; $a$ is the temperature conductivity of concrete; $\lambda$ is the thermal conductivity of concrete; and $\beta$ is the boundary heat transfer coefficient.

According to formulae (3)-(6), the influence range of the concrete temperature change caused by the ambient temperature change is as follows:

$$
x=-\sqrt{\frac{a P}{\pi}} \ln \left[\frac{\Delta T}{A_{0}}\right],
$$

where $\Delta T$ is the temperature variation amplitude of concrete with depth $x$.

Formula (7) was used to calculate the influence range of the gradient temperature difference using the following values of the above-mentioned parameters: $a=0.1 \mathrm{~m}^{2} / \mathrm{d}$, $A=15^{\circ} \mathrm{C}, A_{0}=0.61 \mathrm{~A}$ [19], and $\Delta T=2^{\circ} \mathrm{C}$ at depth $x$. This means that when $\Delta T$ is less than $2^{\circ} \mathrm{C}$, the temperature of the concrete with depth $x$ is not affected by the ambient temperature. Finally, $x$ was calculated to be $24.7 \mathrm{~cm}$. Therefore, we considered that the influence range of the temperature difference in a single pipe of the main arch section was $25 \mathrm{~cm}$.

To verify the accuracy of temperature difference influence range, relevant data from the measuring points in the test arch were statistically analysed. The temperature data from vertical measuring points $1,2,4,6$, and 7 were selected for the analysis, and these data are presented in Figure 6. Cluster analysis was performed on the temperature data from each measuring point, and the analysis results are shown in Figure 7. Finally, these temperature data were analysed statistically, and the results are presented in Table 3. 


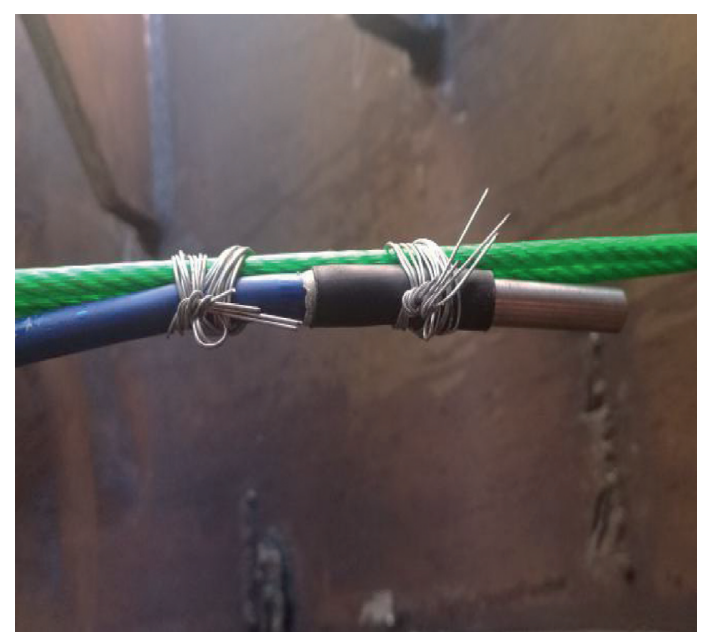

(a)

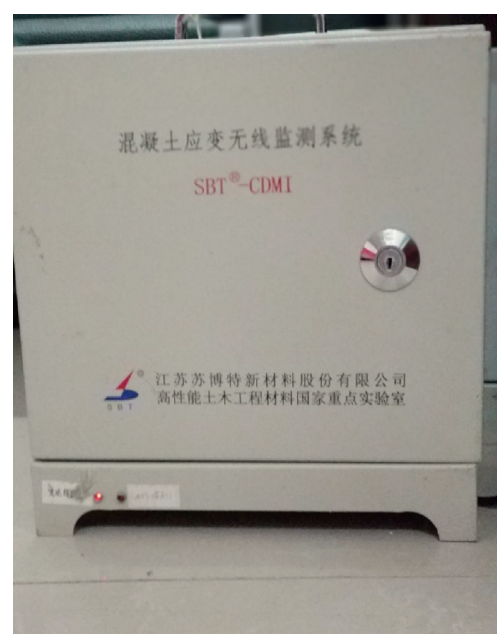

(b)

Figure 4: (a) Temperature sensor and (b) wireless data acquisition instrument.

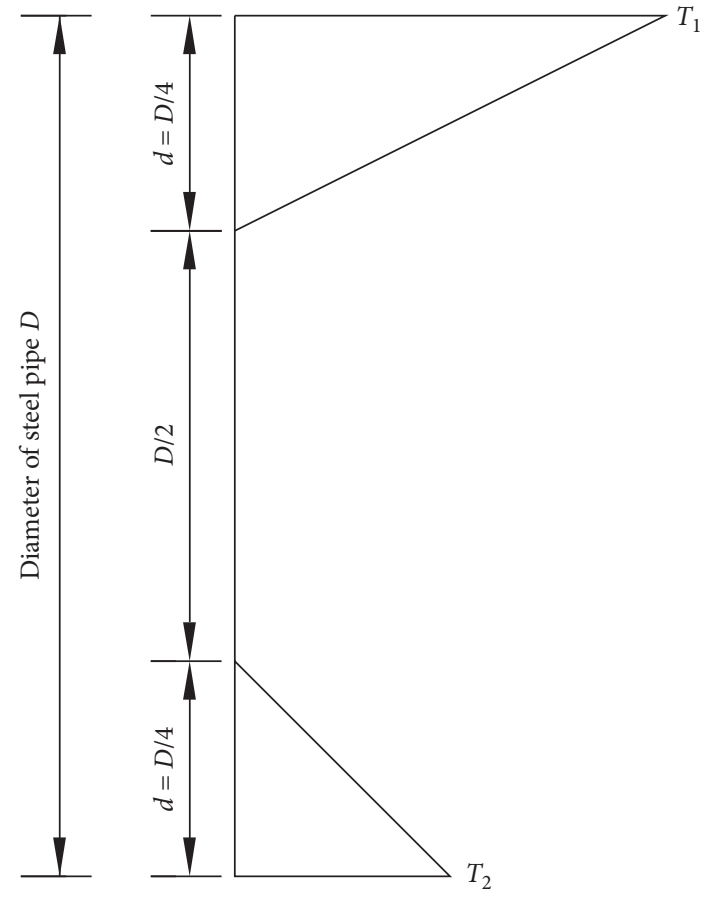

FIGURE 5: Gradient temperature difference curve as per the Chinese code.

On comparing the temperature change curves corresponding to measuring points 2,4 , and 6 , we found that the change trends for the three curves were similar in summer and in winter, and the temperature differences were small. The change ranges observed for the curves corresponding to measuring points 1 and 7 were obviously different from those corresponding to measuring points 2,4 , and 6 .

As observed in Figure 7, the temperature data from measuring points 2,4 , and 6 were classified into one category through cluster analysis, and those from measuring points 1 and 7 were classified into another category through cluster analysis.
TABLE 2: Temperature differences $T_{1}$ and $T_{2}$ specified in the Chinese code $\left({ }^{\circ} \mathrm{C}\right)$.

\begin{tabular}{lcc}
\hline Steel pipe surface coating & \multicolumn{2}{c}{ Single pipe main arch } \\
& $T_{1}$ & $T_{2}$ \\
\hline Dark (red, grey) & 12 & 6 \\
Light (white, silver, etc.) & 8 & 6 \\
\hline
\end{tabular}

On comparing the statistical data of each measuring point presented in Table 3, we observed that the differences between the average and median values of the data from measuring points 2,4 , and 6 were considerably small and within $2^{\circ} \mathrm{C}$; this finding indicates that the average temperatures at measuring points 2,4 , and 6 were extremely close. Further, on comparing the variance and extreme values of the data from measuring points 2,4 , and 6 , we found that the differences were small, indicating that the dispersions of the data recorded at measuring points 2, 4, and 6 are similar.

According to the results obtained from the temperature change curves, cluster analysis, and statistical analysis for the data at each measuring point, the temperature changes at measuring points 2,4 , and 6 were the same, and the vertical gradient temperature difference in the section was considered as the temperature difference between measuring points 1 and 2 and that between measuring points 6 and 7 . Theoretical calculations and experimental temperature data analysis indicated that the influence range of the gradient temperature difference was $25 \mathrm{~cm}$. When the influence range of gradient temperature difference is small, it is considered that the temperature changes rapidly in a small range, which has a great influence on the structure. So the smaller influence range of gradient temperature difference was safe for design calculation.

According to the Chinese code, the influence range of the gradient temperature in the test should be $40 \mathrm{~cm}$, which is obviously different from the value obtained in the test. Moreover, the Chinese code is not applicable in this case. The maximum influence range of the gradient temperature 

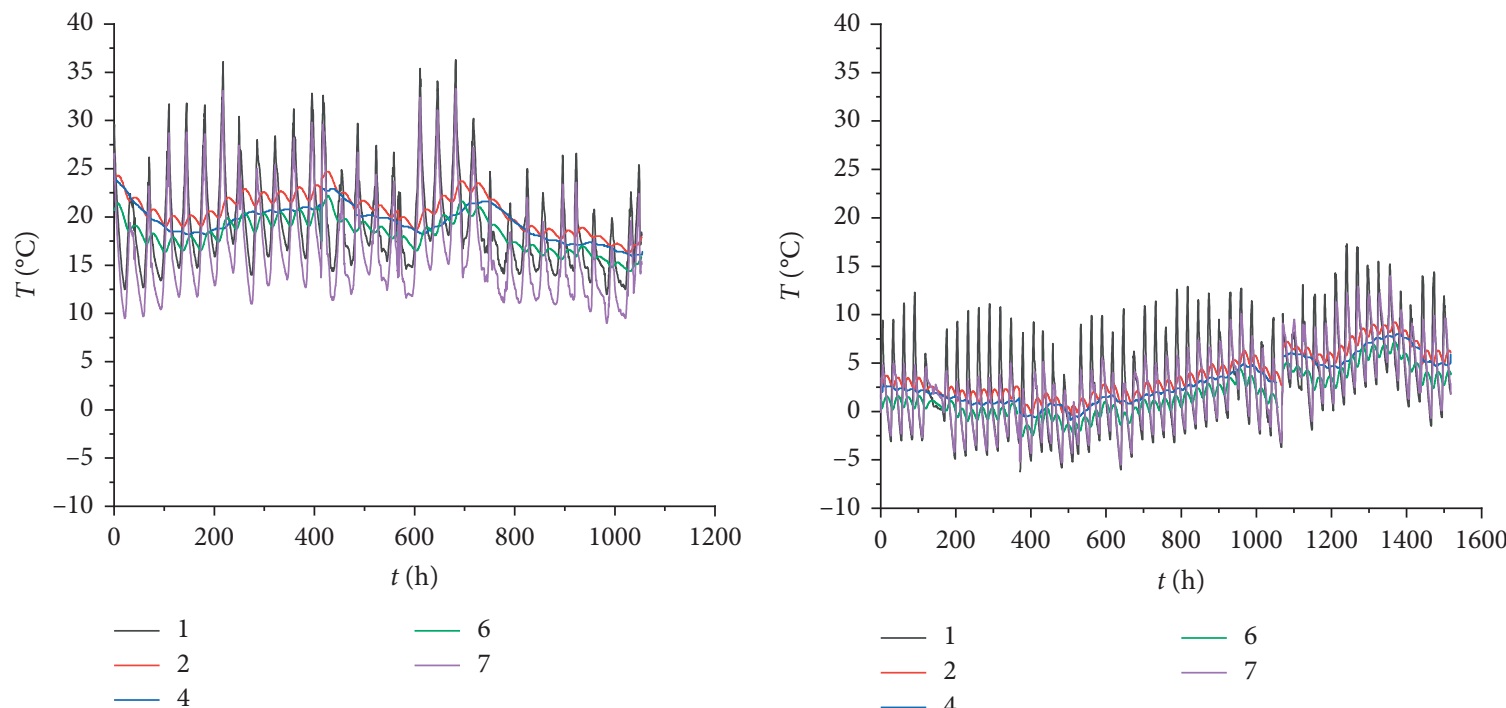

(a)

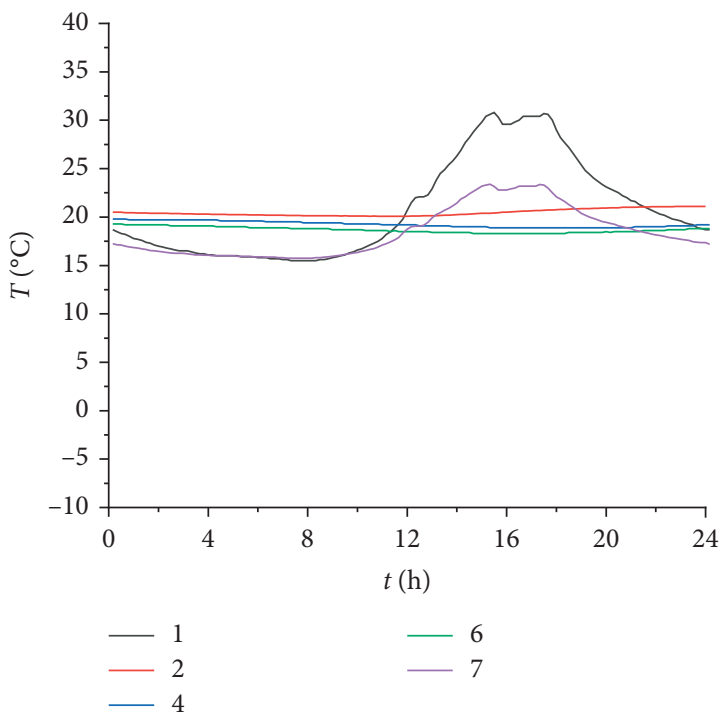

(c)

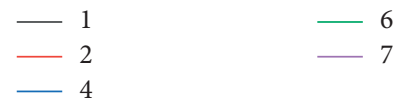

(b)
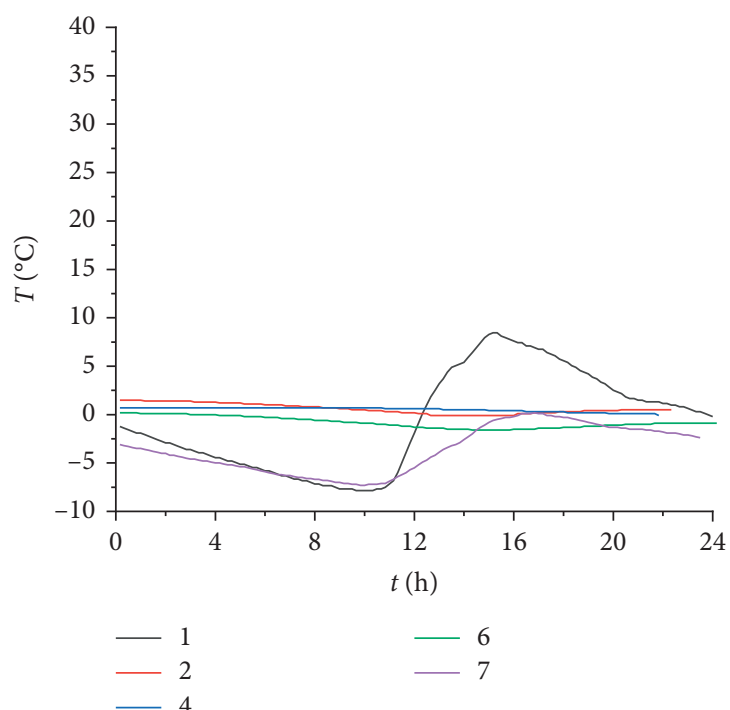

(d)

FIgURE 6: Temperature data obtained from measuring points. (a) Summer, (b) winter, (c) one day in summer, and (d) one day in winter.

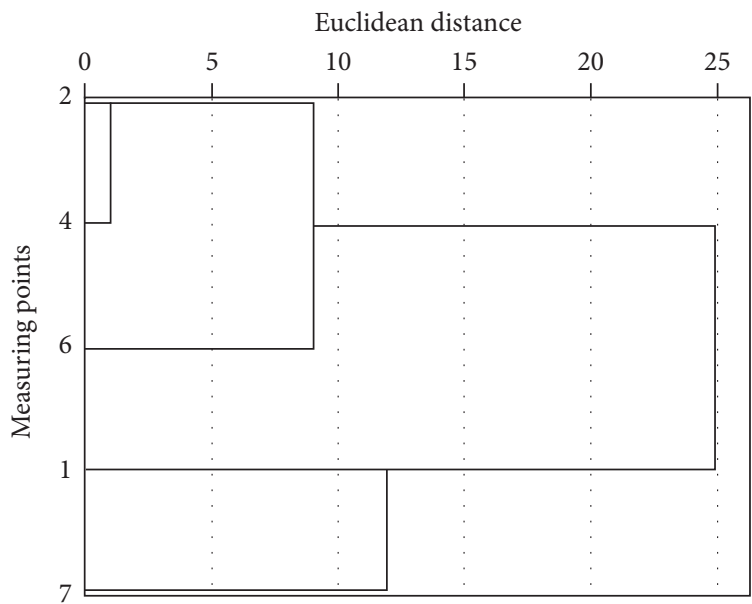

Figure 7: Cluster analysis results of temperature data from measuring points. 
TABLE 3: Statistical analysis results of temperature data $\left({ }^{\circ} \mathrm{C}\right)$.

\begin{tabular}{|c|c|c|c|c|c|c|c|c|c|c|}
\hline \multirow{2}{*}{ Measuring point } & \multicolumn{5}{|c|}{ Summer } & \multicolumn{5}{|c|}{ Winter } \\
\hline & 1 & 2 & 4 & 6 & 7 & 1 & 2 & 4 & 6 & 7 \\
\hline Average & 19.4 & 20.6 & 19.5 & 18.3 & 19.0 & 3.0 & 2.4 & 3.0 & 1.7 & 2.5 \\
\hline Median & 18.2 & 20.7 & 19.7 & 18.4 & 18.4 & 2.5 & 3.2 & 2.4 & 1.2 & 2.4 \\
\hline Variance & 21.0 & 3.7 & 3.0 & 3.1 & 18.7 & 21.3 & 5.8 & 5.4 & 5.2 & 14.1 \\
\hline Minimum & 12.0 & 16.3 & 15.9 & 14.4 & 10.1 & -6.2 & -0.5 & -0.9 & -2.6 & -5.5 \\
\hline Maximum & 36.3 & 24.7 & 24.2 & 22.2 & 32.4 & 17.3 & 9.2 & 8.0 & 7.2 & 14.0 \\
\hline
\end{tabular}

difference in the single pipe was $0.25 \mathrm{~m}$. When the diameter of steel pipe was greater than $0.5 \mathrm{~m}$, the influence range of gradient temperature was $0.25 \mathrm{~m}$; when the diameter of the steel pipe was less than $0.5 \mathrm{~m}$, the influence range of gradient temperature was equal to the pipe radius.

3.2. Single Pipe Gradient Temperature Differences $T_{1}$ and $T_{2}$. To obtain the characteristic values of the temperature gradients in a single pipe, the measured temperature fields in the test arch under sunlight were analysed statistically. The temperature difference data for measuring points 1 and 2 (corresponding to $T_{1}$ in Chinese code) and measuring points 6 and 7 (corresponding to $T_{2}$ in Chinese code) are plotted in Figure 8.

The temperature differences were obtained by comparing different probability density functions, and a lognormal distribution function was selected to fit the gradient temperature differences. The lognormal distribution function is expressed as

$$
f(x)=y_{0}+\frac{A}{\sqrt{2 \pi} w\left(x+x_{0}\right)} \exp \left\{-\frac{\left[\operatorname{In}\left(x+x_{0}\right) / x_{c}\right]^{2}}{2 w^{2}}\right\} .
$$

Figure 9 shows the temperature probability density histograms for the temperature differences and the fitting curve obtained through statistical analysis. The relevant parameters of the fitting curves are listed in Table 4.

The method for calculating the standard values is not specified in the Chinese code [20]. Therefore, referring to the European structural design standard I [21], the characteristic temperature value with a 50 -year return period was used as the standard temperature value. According to the design reference period of 100 years specified in the Chinese bridge code, the mathematical expectation of the number of times that the maximum temperature exceeded the standard value in the design reference period was two. This implies that the probability of the temperature exceeding the standard value is $2 \%$. The probability of exceeding is calculated as follows:

$$
F(x)=1-\int_{-\infty}^{T} f(x) \mathrm{d} x .
$$

Using formulae (8) and (9), we calculated the minimum integer $T$, which satisfies the exceedance probability of $2 \%$; it is the standard value of the temperature difference with a return period of 50 years. According to the analysis, the standard temperature difference value can be calculated using the probability density statistical model for the temperature samples. The integer solutions satisfying the 50 year return period are given in Table 5 .

On comparing the statistical analysis results with the standard values, it was found that the calculated standard value was $4^{\circ} \mathrm{C}$ higher than the standard value in Chinese standard. Based on the experimental and statistical analysis results and considering the low data count for the temperature sample and the influence of error, $16^{\circ} \mathrm{C}$ and $10^{\circ} \mathrm{C}$ were, respectively, considered the upper and lower gradient temperature differences.

The obtained values of the gradient temperature differences in single pipes and those specified in the Chinese code are all positive temperature gradients; that is, the analysis was conducted under conditions with a high external temperature and low internal temperature of main arch section. Therefore, Figures 6(c) and 6(d) show that the external temperature of the main arch section is low, and the internal temperature is high at night. At this time, the gradient temperature differences, $T_{1}$ and $T_{2}$, are negative. There are limited results and specifications available to quantitatively analyse the negative temperature gradient of single pipes. Therefore, in this study, the negative temperature gradient of the single tube was analysed based on the standards specified in the Chinese code and gradient curve, given in Table 2 and Figure 5, respectively.

Moreover, considering that the exceedance probability is $2 \%$, the formula for calculating the exceedance probability of the negative gradient temperature difference is as follows:

$$
F(x)=1-\int_{T}^{+\infty} f(x) \mathrm{d} x
$$

Using formulae (1) and (3), we calculated the maximum integer solution showing an exceedance probability of $2 \%$ and considered it the standard value of the negative gradient temperature difference with a return period of 50 years. The calculation results are listed in Table 6 .

Comparing the data in Tables 5 and 6, we found that the absolute value of the negative gradient temperature difference in the single tube was less than that of the positive gradient temperature difference. Moreover, the negative values of $T_{1}$ and $T_{2}$ were close. To simplify the analysis when studying the influence of the negative gradient temperature difference on the bridge structure, both the negative gradient temperature differences, $T_{1}$ and $T_{2}$, were set to $-8^{\circ} \mathrm{C}$. 
TABLE 4: Estimated parameters of probability density statistical model.

\begin{tabular}{|c|c|c|c|c|c|c|c|}
\hline \multirow[t]{2}{*}{ Season } & \multirow[t]{2}{*}{ Temperature difference type } & \multicolumn{6}{|c|}{$\begin{array}{l}\text { Estimation of the probability density parameters of the gradient temperature } \\
\text { differences in the cross section of a single circular pipe }\end{array}$} \\
\hline & & $y_{0}$ & A & $x_{0}$ & $x_{c}$ & $w$ & Similarity \\
\hline Summer & $\begin{array}{l}T_{1} \\
T_{2}\end{array}$ & $\begin{array}{c}0.007 \\
0.0003 \\
\end{array}$ & $\begin{array}{l}0.789 \\
1.012 \\
\end{array}$ & $\begin{array}{c}9 \\
10 \\
\end{array}$ & $\begin{array}{l}8.316 \\
7.900 \\
\end{array}$ & $\begin{array}{l}0.350 \\
0.458\end{array}$ & $\begin{array}{l}0.927 \\
0.973 \\
\end{array}$ \\
\hline Winter & $\begin{array}{l}T_{1} \\
T_{2}\end{array}$ & $\begin{array}{l}-0.0024 \\
-0.006 \\
\end{array}$ & $\begin{array}{l}1.120 \\
1.191\end{array}$ & $\begin{array}{l}8 \\
5\end{array}$ & $\begin{array}{l}6.895 \\
5.912 \\
\end{array}$ & $\begin{array}{l}0.701 \\
0.657 \\
\end{array}$ & $\begin{array}{l}0.970 \\
0.940 \\
\end{array}$ \\
\hline
\end{tabular}

TABLE 5: Standard values of gradient temperature differences in single tube $\left({ }^{\circ} \mathrm{C}\right)$.

\begin{tabular}{lccccc}
\hline Season & \multicolumn{2}{c}{ Summer } & \multicolumn{2}{c}{ Winter } & \multicolumn{2}{c}{ Code } \\
\hline Temperature difference types & $T_{1}$ & $T_{2}$ & $T_{1}$ & $T_{2}$ & $T_{1}$ \\
Standard values of temperature differences & 16 & 10 & 10 & 8 & $T_{2}$ \\
\hline
\end{tabular}

TABLE 6: Standard values of negative gradient temperature differences in single tube $\left({ }^{\circ} \mathrm{C}\right)$.

\begin{tabular}{|c|c|c|c|c|}
\hline Season & \multicolumn{2}{|c|}{ Summer } & \multicolumn{2}{|c|}{ Winter } \\
\hline Temperature difference type & $T_{1}$ & $T_{2}$ & $T_{1}$ & $T_{2}$ \\
\hline Standard values of negative temperature differences & -8 & -7 & -7 & -4 \\
\hline
\end{tabular}

\section{Conclusion}

In this study, a long-term continuous temperature observation experiment involving a large-scale test arch was conducted in Tibet. Large volumes of test data were statistically analysed to verify the influence range of the gradient temperature difference in a single circular pipe. The probability distribution function form of the gradient temperature difference was obtained in addition to the standard values of the temperature differences corresponding to a 50-year return period. The findings of this study can serve as references for determining the temperature load parameter values using the Chinese bridge design codes. The following conclusions can be drawn from the study:

(1) The maximum influence range of the gradient temperature difference in a single pipe was $0.25 \mathrm{~m}$. When the diameter of the steel pipe was greater than $0.5 \mathrm{~m}$, the influence range of gradient temperature was $0.25 \mathrm{~m}$; when the diameter was less than $0.5 \mathrm{~m}$, the influence range of the gradient temperature was equal to the pipe radius.

(2) The vertical temperature difference in the single pipe of the bridge in Tibet followed a lognormal distribution.

(3) The vertical gradient temperature differences of the single pipe (positive $T_{1}=16^{\circ} \mathrm{C}$ and $T_{2}=10^{\circ} \mathrm{C}$; negative $T_{1}=T_{2}=-8^{\circ} \mathrm{C}$ ) were obtained from the lognormal distribution function, for which the return period was 50 years.

These results are considerably different from the standards specified in the Chinese bridge design codes. Therefore, the gradient temperature differences calculated in this study must be used for the calculations involving arch bridges in Tibet with single circular pipes in the main arches.
The period of this study was only one year, and there were not enough temperature samples. We intend to conduct another study with more temperature samples spanning several years. Furthermore, as there are some differences between the test arch and actual CFST arch bridge, a long-term real bridge test is necessary to verify the results of this test.

\section{Data Availability}

The data used to support the findings of this study are included within the Supplementary Materials files.

\section{Conflicts of Interest}

The authors declare that there are no conflicts of interest regarding the publication of this paper.

\section{Acknowledgments}

This research was funded by the National Natural Science Foundation of China (Grants nos. 51738004, 51868006, and 51878186), by the Major Science and Technology Foundation of Guangxi (Grant no. AA18118029), and by Project of Science and Technology Research and Development Plan of China Railway Corporation (2017G006-B).

\section{Supplementary Materials}

Supplementary Figures 8 and 9: single pipe gradient temperature difference analysis. (Supplementary Materials)

\section{References}

[1] J. Zheng, "Development and prospect of long-span arch bridge," China Journal of Highway and Transport, vol. 3, pp. 41-42, 2017. 
[2] J. Zheng and J. Wang, "Concrete-filled steel tube arch bridges in China," Engineering, vol. 4, no. 1, pp. 143-155, 2018.

[3] Y. Zheng, J. Wang, Z. Feng et al., "Vacuum assisted technology test of concrete filled steel tubular arch," China Journal of Highway and Transport, vol. 27, pp. 44-50, 2014.

[4] Y. Liu, J. Liu, and N. Zhang, "Summary of the effect of sunshine temperature on bridge structure," Journal of Civil Engineering, vol. 52, pp. 59-78, 2019.

[5] J. Liu, Y. Liu, C. Zhang, Q. Zhao, Y. Lyu, and L. Jiang, "Temperature action and effect of concrete-filled steel tubular bridges: a review," Journal of Traffic and Transportation Engineering (English Edition), vol. 7, no. 2, pp. 174-191, 2020.

[6] G.-x. Wang, Y.-1. Ding, X.-j. Wang, X. Yan, and Y.-f. Zhang, "Long-term temperature monitoring and statistical analysis on the flat steel-box girder of Sutong bridge," Journal of Highway and Transportation Research and Development (English Edition), vol. 8, no. 4, pp. 63-68, 2014.

[7] G. Wang, Y. Ding, A. Li et al., "Study on transverse temperature difference characteristics of steel box girder of Runyang bridge based on long-term monitoring data," Engineering Mechanics, vol. 30, pp. 163-167, 2013.

[8] J. F. Wang, Z. Y. Xu, X. L. Fan et al., "Thermal effects on curved steel box girder bridges and their countermeasures," Journal of Performance of Constructed Facilities, vol. 31, no. 2, Article ID 04016091, 2017.

[9] L. Leanne, L. R. Keri, and G. B. Ian, "Bridge temperature profiles revisited: thermal analyses based on recent meteorological data from Nevada," Journal of Bridge Engineering, vol. 25, no. 1, Article ID 04019124, 2020.

[10] L. Zhou, Y. Xia, M. W. James et al., "Temperature analysis of a long-span suspension bridge based on field monitoring and numerical simulation," Journal of Bridge Engineering, vol. 21, Article ID 04015027, 2016.

[11] X. Lei, H. Jiang, and J. Wang, "Temperature effects on horizontally curved concrete box-girder bridges with singlecolumn piers," Journal of Aerospace Engineering, vol. 32, Article ID 04019008, 2019.

[12] J. Liu, Y.-j. Liu, G.-l. Liu, and N. Zhang, "Measurement and simulation of temperature field of concrete box girder in northwest severely cold area," Journal of Highway and Transportation Research and Development (English Edition), vol. 12, no. 3, pp. 37-45, 2018.

[13] J. Lin, B. Bruno, J. Xue et al., "Temperature monitoring and response of deck-extension side-by-side box girder bridges," Journal of Performance of Constructed Facilities, vol. 34, no. 2, Article ID 04019122, 2020.

[14] D. Li, A. Marc, and H. Walter, Evaluation of Temperature Data of Confederation Bridge: Thermal Loading and Movement at Expansion Joint, Structures Congress, Vancouver, British Columbia, Canada, 2008.

[15] X. Song, M. Hani, J. Li et al., "Effects of solar temperature gradient on long-span concrete box girder during cantilever construction," Journal of Bridge Engineering, vol. 21, Article ID 04015061, 2016.

[16] L. E. Rodriguez, P. J. Barr, and M. W. Halling, "Temperature effects on a box-girder integral-abutment bridge," Journal of Performance of Constructed Facilities, vol. 28, no. 3, pp. 583-591, 2014.

[17] JTG/TD65-06-2015, Design Code for Concrete Filled Steel Tubular Arch Bridge of Highway, China Communications Press, Beijing, China, 2015.

[18] T. Shi, J. Zheng, N. Deng et al., "Temperature load parameters and thermal effects of a long-span concrete-filled steel tube arch bridge in Tibet," Advances in Materials Science and Engineering, vol. 2020, Article ID 9710613, 11 pages, 2020.

[19] B. Zhu, Temperature Stress and Temperature Control of Mass Concrete, China Electric Power Press, Beijing, China, 1999.

[20] GBT50283-1999, Unified Standard for Reliability Design of Highway Engineering, China Communications Press, Beijing, China, 1999.

[21] J. R. Hosking, "L-moments: analysis and estimation of distributions using linear combinations of order statistics," Journal of the Royal Statistical Society: Series B (Methodological), vol. 52, no. 2, pp. 105-122, 1990. 